\title{
Imagem da enfermeira: revisão da literatura
}

\author{
Nurse's image: literature review \\ Imagen de la enfermera: revisión de la literatura
}

Taís Maria Nauderer

Enfermeira.

Aluna do Programa de Mestrado da UFRGS.

Bolsita do CAPES

\section{Maria Alice Dias da Silva Lima}

Enfermeira.

Doutora em Enfermagem

Professor Adjunto da Escola de Enfermagem da

UFRGS.

Artigo baseado no trabalho de conclusão do curso de Graduação em Enfermagem da Universidade Federal do Rio Grande do Sul (UFRGS).

\section{RESUMO}

A imagem que a sociedade constrói da enfermeira é permeada por estereótipos que incluem figuras como santas, prostitutas, feiticeiras, heroínas e se relacionam à função de auxiliar do médico e à falta de vida social. Além disso, a imagem que as enfermeiras têm de si próprias e de seu trabalho é negativa, ocasionando frustração pela falta de autonomia encontrada na realidade profissional. Para uma melhor compreensão desse problema, realizou-se uma revisão bibliográfica, que teve como objetivo caracterizar e analisar a imagem da enfermeira. Considera-se pequena a produção científica sobre o tema no país. Conclui-se que os estereótipos da imagem influenciam negativamente sua prática e que na história da Enfermagem se encontram muitas das razões para as distorções existentes.

Descritores: Papel do profissional de enfermagem; Prática profissional/história; História da enfermagem.

\section{ABSTRACT}

The society's image about the nurses is permeated of stereotypes that include figures like saints, prostitutes, witches, heroines and are related to the function of assisting doctors and to a lack of social life. Moreover, the image that the nurses have of themselves and of their work is negative, causing frustration for the lack of autonomy found on the professional reality. Seeking for a better understanding of this problem, a literature review was proceeded, aiming to characterize and analyze the nurse's image. The national scientific production is considered small on the subject. Conclusions indicate that stereotypes negatively influence nursing practice and that in Nursing history it is found many reasons for the existing distortions.

Descriptors: Nurse's role; Professional practice/history; History of nursing.

\section{RESUMEN}

La imagen que la sociedad tiene sobre las enfermeras se impregna de estereotipos que incluyen figuras como santas, prostitutas, brujas, heroínas y se relacionan con la función de asistir a doctores y con una carencia de vida social. La imagen que las enfermeras tienen de sí mismas y de su trabajo es negativa, causando frustración debido a carencia de autonomía encontrada en la realidad profesional. Para una comprensión mejor do problema, fue hecha una revisión bibliográfica, que tenía como objetivo caracterizar y analizar la imagen de la enfermera. La producción científica é pequeña en el tema, en el país. Las conclusiones son que los estereotipos influencian negativamente su práctica y que en la historia del oficio están encontrado muchas de las razones de las distorsiones existentes.

Descriptores: Rol de la Enfermera; Practica Profesional/historia; Historia de la Enfermería.

Nauderer TM, Lima MADS. Imagem da enfermeira: revisão da literatura. Rev Bras Enferm 2005 jan-fev; 58(1):747.

\section{INTRODUÇÃO}

A imagem da enfermeira (será utilizado o substantivo feminino, de acordo com a designação cultural genérica utilizada para essa categoria profissional), conforme identificada pela sociedade, compõe-se de estereótipos, demonstrando desconhecimento sobre esse trabalho ou caráter depreciativo em relação à profissão. A figura da enfermeira é identificada com distorções e, muitas vezes, com desvalorização social, devido à idéia de que a profissão tem baixa remuneração e é subalterna a outros profissionais, especialmente ao médico.

Levando-se em conta a desinformação da população em relação à realidade profissional, surgem algumas questões: Qual a imagem utilizada pela sociedade para identificar a enfermeira? Quais são os fatores que influenciam a construção dessa imagem? Houve alguma mudança nessa imagem em algum momento?

Assim, este artigo apresenta uma revisão teórica acerca do tema, propondo reflexões a partir desses questionamentos.

\section{IMAGEM}

A imagem significa o quadro que uma pessoa tem do objeto de sua vivência. Seu conceito está intimamente ligado à idéia de prestígio social e sua construção relaciona-se a concepções, sentimentos e atitudes. Imagem pode significar também a opinião (contra ou a favor) que o público 
pode ter de uma instituição, organização ou personalidade ou ainda o conceito que uma pessoa goza junto a outrem ${ }^{(1)}$.

A imagem de qualquer categoria profissional na sociedade pode ser associada a poder, reconhecimento e status. $O$ que a sociedade pensa do profissional é tão importante quanto aquilo que ele é, pois a projeção de uma imagem negativa dificulta 0 desenvolvimento da profissão e 0 seu reconhecimento por parte da sociedade ${ }^{(2)}$.

A imagem profissional da enfermeira é uma rede de representações sociais da profissão. Para Silva, Padilha e Borenstein (3:588) "é representada por um conjunto de conceitos, afirmações e explicações, reproduz e é reproduzida pelas ideologias originadas no contexto das práticas sociais, internas/externas a ela".

Assim, a imagem profissional remete à identidade da profissão, relacionada às suas características e significados exclusivos. Essa relação imagem/identidade é um fenômeno histórico, social e político, configurando-se em uma totalidade contraditória, múltipla e mutável( ${ }^{(3)}$.

\section{História da Enfermagem}

A imagem da enfermeira é influenciada pela história da enfermagem. As primeiras referências a enfermeiras são encontradas no Velho Testamento Bíblico. A palavra enfermeira é derivada do latim nutrix que corresponde à "mãe enfermeira", imagem associada a uma mulher que acompanhava uma criança que geralmente não era sua, como uma babá. Ao longo dos séculos a palavra "enfermeira" evoluiu até ser associada a uma pessoa que cuida de enfermos, não necessariamente do sexo feminino(4).

A Enfermagem surgiu como uma resposta intuitiva ao desejo de manter as pessoas saudáveis, proporcionar conforto e proteção aos doentes, constituindo a Imagem Folclórica da Enfermeira ${ }^{(5)}$. O papel de enfermeira era assumido por aquelas mulheres que apresentavam desejo e habilidade para cuidar. $\mathrm{O}$ conhecimento que essas mulheres desenvolviam e acumulavam sobre saúde era passado oralmente de geração para geração. Naquela época existia uma relação íntima da religião e do folclore com as artes curativas ${ }^{(6)}$.

A Imagem Religiosa da Enfermeira( ${ }^{(5)}$ se desenvolveu na Era Cristã e Idade Média, com organizações voltadas para a caridade e o cuidado de doentes, pobres, órfãos, viúvos, idosos, escravos e prisioneiros ${ }^{(4)}$. Nessa fase, as mulheres solteiras (diaconisas), as virgens e as viúvas tiveram oportunidades de trabalho jamais imaginadas. À medida que a Enfermagem desenvolvia uma imagem associada à religião, uma disciplina cada vez mais rígida era exigida e a obediência absoluta às ordens médicas e dos pastores era determinada ${ }^{(4)}$.

No passado, os cuidados aos doentes eram considerados como inatos à mulher, inscritos no seu patrimônio genético e associados ao amor maternal. O impacto disso, associado à divisão sexual do trabalho e à influência dos valores religiosos veiculados desde a idade média, colaboram para a desvalorização econômica lenta, mas segura, do conjunto de práticas de cuidado asseguradas pelas mulheres ${ }^{(7)}$. Amor $\mathrm{e}$ doação estão associados ao exercício da obediência e humildade, contribuindo para que faça parte do ideário da sociedade que as enfermeiras trabalhem sempre a serviço do outro, sem uma remuneração justa ou mesmo condições de trabalho que possibilitem um digno exercício da profissão(8).

O Renascimento (séc. XIV a XVI) provocou uma revolta contra a supremacia da Igreja Católica, quando foram dissolvidas ordens religiosas e o trabalho das mulheres nessas ordens foi extinto, iniciando os "Anos Negros da Enfermagem". O papel das mulheres na sociedade mudou: deveriam resignar-se aos limites de seus lares e obedecer a seus maridos. Assim, o cuidado aos doentes foi deixado a cargo de um grupo mulheres que compreendia prisioneiras e prostitutas que eram forçadas a trabalhar como serventes domésticas ${ }^{(4)}$. A Enfermagem naquela época era considerada um serviço doméstico, sendo pouco desejável, em virtude das longas horas, da baixa remuneração e do estressante trabalho. A denominada Imagem Servil da Enfermeira ${ }^{(5)}$ representava uma mulher gorda, velha, bêbada, com uma aparência desagradável, por vezes masculinizada e insensível(4).

As características marcantes de gênero em uma profissão quase que exclusivamente feminina contribuíram com essa imagem de obediência e submissão. Fazia parte da formação advertir as enfermeiras que não era necessário dominar o conhecimento médico, mas realizar tarefas domésticas de rotina, sem julgamento crítico ou iniciativa ${ }^{(9)}$. Com isso eram garantidas a subordinação e a dependência de seu trabalho ao médico, o que interferiu na evolução da profissão, visto que suas precursoras preocupavam-se em enaltecer os valores referentes à beleza dessa atividade e às perspectivas de vida dedicada ao próximo.

No Brasil, a Enfermagem surgiu com elementos exclusivamente do sexo masculino, primeiramente com os índios, nas figuras dos feiticeiros, pajés e curandeiros, que se ocupavam dos cuidados aos que adoeciam em suas tribos, e mais tarde com os jesuítas, voluntários leigos e escravos, selecionados para tal tarefa ${ }^{(10)}$. No Brasil do século XVI, a Enfermagem tinha um cunho essencialmente prático, razão pela qual eram extremamente simplificados os requisitos para o exercício da função de enfermeira. Essa condição perdurou até o início do século $X X$, sendo que, nesse período não era exigido qualquer nível de escolarização para aqueles que exerciam a profissão e a prática era embasada em conhecimentos puramente empíricos ${ }^{(10)}$.

No Brasil, Ana Néri, considerada pelo Governo Brasileiro de sua época a Mãe dos Brasileiros e, até os dias de hoje, símbolo da Enfermagem nacional, tinha como maiores virtudes abnegação, obediência e dedicação, sendo que o Estado Novo institucionalizou seu heroísmo, patriotismo e resignação. Assim, a imagem que permaneceu no país é a de que a enfermeira deveria ser alguém disciplinado e obediente, alguém que não exercesse crítica social, porém socorresse e consolasse as vítimas da sociedade ${ }^{(10)}$.

A primeira escola de enfermeiras no Brasil surgiu em 1890, nas dependências do Hospício Nacional de Alienados, pela necessidade de formação de profissionais de Enfermagem para tal instituição, pois as irmãs de caridade, responsáveis pelos cuidados aos doentes, haviam abandonado o hospício por incompatibilidade com o seu diretor. Essa escola, chamada Alfredo Pinto, era baseada no modelo da Escola de Salpetrière e tinha sua organização e direção realizada por médicos ${ }^{(11)}$. A Escola Ana Néri, fundada em 1923, foi a primeira no Brasil a ministrar o ensino sistematizado de Enfermagem baseado no modelo nightingaleano, a cargo de enfermeiras americanas e foi pioneira também na exigência de escolaridade mínima para ingresso: curso normal ou equivalente ${ }^{(10)}$.

Havia uma desvalorização da profissão de enfermeira no Brasil do início do século passado. Na criação do Serviço de Enfermeiras do Departamento Nacional de Saúde Pública, em 1922, uma das organizadoras evitou em seu discurso utilizar a palavra "enfermeira", preferindo o termo "nurse", ao se referir às profissionais formadas sob sua supervisão, tentando assim diferenciá-las. O termo não teve a aderência esperada, prevalecendo as formas de denominação diferencial com a enfermeira de alto padrão ou diplomada, as quais indicavam uma categoria diferente de profissionais, com uma formação mais exigente $^{(8)}$.

Foi somente no final do ano de 1961, por força de legislação, que a formação de Enfermeiras no Brasil foi incluída no sistema educacional universitário, estabelecendo-se como pré-requisito para ingresso o curso secundário completo ou equivalente. No entanto a idéia de que as enfermeiras são profissionais de baixa qualificação ainda permanece, assim como permanece também a terminologia diferencial adotada a partir da década de $20^{(10)}$.

A formação em Enfermagem no Brasil, que no seu princípio voltavase para as práticas preventivas e para os problemas básicos da maioria da população, foi aos poucos se distanciando disso e acompanhando os avanços do ensino e das práticas médicas, em acordo com o modelo econômico vigente na época. No início da década de 70, as disciplinas de saúde pública não eram mais obrigatórias no currículo mínimo da graduação e o domínio das técnicas avançadas em saúde se fazia necessário, pois as equipes médicas precisavam de enfermeiras especializadas para atuarem em seus centros cirúrgicos sofisticados e afins, para uma assistência muito mais curativa, restrita a uma minoria da população(10). Assim, pode-se depreender que as enfermeiras 
demonstraram não ter buscado manter sua identidade na saúde preventiva, área que embasou seu início como profissão. A formação voltada para as práticas hospitalares reforçou o estereótipo de auxiliar dos médicos, pois partiu deles a necessidade de especialização e distanciamento da saúde pública, por motivos financeiros que muito pouco atingiam as enfermeiras.

\section{IMAGEM DA ENFERMEIRA}

A imagem da enfermeira é uma preocupação mundial, tendo em vista a produção científica acerca do tema encontrada na literatura, indicando que há décadas 0 assunto é pertinente e merece a atenção dos profissionais. Artigos recentes têm sido produzidos na Austrália(12,13) China ${ }^{(14)}$ e Egito ${ }^{(15)}$, mostrando que o tema é objeto de estudo de relevância para a Enfermagem.

A profissão de Enfermagem evoluiu, assim como seu ensino, porém a figura da enfermeira hoje é ainda permeada pelos conceitos e estereótipos associados à função de auxiliar o médico e à falta de vida social pela total dedicação à profissão(4,12), à figura de fadas e feiticeiras ${ }^{(9)}$ e até ao erotismo e sensualidade ${ }^{(16)}$.

São numerosas as referências associando as enfermeiras a figuras de anjos de branco, santas e religiosas, que podem ser explicadas tanto na cor predominante dos uniformes ou nas origens da profissão, como nas virtudes desejadas tanto para as religiosas como para as enfermeiras, tais como: obediência, respeito à hierarquia e humildade ${ }^{(10)}$. As enfermeiras também são vistas como anjos que protegem vidas humanas, aproximando-se muitas vezes a super-heróis, que não sentem dores, não têm necessidades, horários ou família ${ }^{(8)}$.

O caráter manual atribuído ao cuidado direto aos doentes contribui para sua desvalorização, visto que as atividades práticas são percebidas como de inferioridade em relação ao trabalho intelectual, próprio do médico, e como fator de desvalorização social(17,18). Outro aspecto relevante trata dos diferentes graus de formação da equipe de Enfermagem, dos quais a sociedade, de um modo geral não percebe a diferença, quando é atendida por esses profissionais. A falta de identificação dos níveis dos profissionais de enfermagem ocasiona frustração e diminui o desejo dos estudantes e dos profissionais de continuarem na profissão, sendo mais simples procurar outra, que tenha maior reconhecimento e valorização social(8)

A formação em Enfermagem não tem contribuído para a mudança na postura e, conseqüentemente, na imagem da enfermeira. A educação em Enfermagem ainda carrega a concepção de que as enfermeiras devem ser disciplinadas e obedientes, sem valorizar em suas atividades de ensino o desenvolvimento de uma postura crítica, dando prioridade a aspectos de conduta e moral(19).

O agrupamento dos diversos fatores acima descritos, associado ao baixo status social e à falta de estabelecimento de limites de atuação, denota nas profissionais insatisfação e sentimentos de impotência e pessimismo diante dos rumos da profissão(17). Em associação e/ou decorrência disso, a imagem que as enfermeiras têm de si também é negativa, o que contribui para um baixo grau de auto-realização. A autoimagem da enfermeira é uma responsabilidade da educação em Enfermagem, espaço no qual os professores deveriam estimular o desenvolvimento do autoconceito e da auto-estima positivos nos alunos, para embasar mudanças significativas na imagem profissional, tornandoa mais positiva(2)

Um estudo realizado sobre a imagem da enfermeira na imprensa escrita ${ }^{(20)}$ concluiu que a enfermeira não é devidamente reconhecida pelo público, sendo confundida com os outros trabalhadores em Enfermagem e até com diferentes profissionais da área da saúde, como nutricionistas e fisioterapeutas. Concluiu-se também que a função gerencial do trabalho é pouco expressiva e as atividades de pesquisa da enfermeira são desconhecidas, havendo, respectivamente, uma e nenhuma referência a estas dimensões. Entretanto, nem só de aspectos negativos sua imagem é constituída: foi constatada a utilização do termo enfermeira como sinônimo de prestação de cuidados, com conotação de carinho e eficiência. Mesmo assim, a análise das autoras desse trabalho mostra que o espaço ocupado pela Enfermagem na imprensa tem contribuído para reforçar aspectos negativos, distantes da imagem que as enfermeiras fazem de si mesmas. Em outro estudo(2), realizado com alunos ingressantes no curso, a influência da mídia na imagem pública da enfermeira não é tão determinante quanto parece, pois esse fator ficou em $4^{\circ}$ lugar dentre os que influenciaram a imagem atribuída à enfermeira pelos acadêmicos, tendo menos influência que experiências vivenciadas em situações de doença, relacionamento com familiares ou amigas que sejam enfermeiras e antecedentes de trabalho no campo da saúde.

Há ainda autoras ${ }^{(16)}$ que, mesmo referindo em seus estudos a falta de definição da imagem da enfermeira, o que possibilita incômodas interpretações e representações por parte da sociedade, defendem que é nessa falta de delineamento que reside a força da imagem da enfermeira, pois assim "ela pode metamorfosear-se em formas tão ricas e sedutoras"(16:35). A Enfermagem deveria alargar suas percepções e não valorizar tanto os estereótipos, tais como o da enfermeira prostituta que, na tentativa de ser combatido, acabou por instituir a rigidez moralizante da conduta profissional. Essa situação é classificada como um diálogo de surdos, no qual ataca-se a forma com o conteúdo.

Identificam-se diferentes correntes sócio-econômicas que influenciam as práticas de Enfermagem, entre elas a tecnicidade, a revalorização entre quem presta e quem recebe cuidados e o desenvolvimento em saúde. Essas influências modificam o papel da enfermeira, bem como as expectativas desse papel e, assim, a imagem da enfermeira também se transforma à medida que é abalada a estabilidade do papel. A Enfermagem é identificada com uma formação religiosa matrilinear $e$ uma formação médica patrilinear e, para distanciar-se de suas origens religiosas, as enfermeiras procuraram especializar-se na tecnicidade, reforçando dessa forma sua associação ao médico(7). Ou seja, para tentar desvencilhar-se de um estereótipo, as enfermeiras acabam por aproximarem-se de outro, o que contribui para a confusão de seu papel e de sua imagem.

A contradição central que atravessa a profissão de Enfermagem é a que se estabelece entre o reconhecimento do papel psicossocial como o papel dominante da profissão, pretensamente concessor de uma verdadeira autonomia em relação ao médico, e o fato de o seu estatuto social na equipe de saúde ser totalmente determinado pela posição objetiva na produção dos cuidados, que 0 associa ao tecnicismo e à tecnologia, novamente aproximado ao trabalho do médico(21).

A discrepância entre a percepção das enfermeiras sobre a imagem pública de sua profissão e a sua própria percepção como profissional prejudica o potencial de sua prática e reforça a incongruência entre a ideal e a atual realidade profissional(12). Alguns fatores contribuem para a manutenção dos estereótipos da imagem da enfermeira, tais como a existência de hierarquia entre médico e enfermeira, a condição feminina da profissão, o reforço da mídia ao reproduzir as tradicionais imagens das enfermeiras. Assim, uma melhoria na imagem pública da enfermeira se faz essencial(12).

\section{CONSIDERAÇÕES FINAIS}

As informações acerca da imagem da enfermeira relatadas na literatura, em sua maioria, remetem à história da Enfermagem como profissão e à sua evolução, relacionadas ao momento histórico, mais especialmente ao papel da mulher em cada época. Esses aspectos influenciam significativamente a imagem da enfermeira nos dias de hoje e, mesmo que ocorridos em determinados períodos históricos, separados por grandes espaços de tempo, misturam-se no momento atual, provocando um anacronismo e dificultando ainda mais a definição de uma identidade profissional da enfermeira.

Considera-se pequena a produção científica sobre o tema no país, uma vez que é de grande relevância. Entende-se que a imagem pública da enfermeira influencia sua prática profissional, pois a opinião pública é considerada poderosa na determinação da estrutura social e nas normas da sociedade. Assim, clarificar os impactos dos estereótipos públicos da imagem da enfermeira pode corroborar para aumentar sua credibilidade na imagem pública ${ }^{(12)}$. Mais estudos precisam ser realizados, tanto na tentativa de definir melhor a imagem pública da enfermeira como na proposição de medidas que possam contribuir para mudar esta realidade. 


\section{REFERÊNCIAS}

1. Dorsch F. Dicionário de Psicologia Dorsh. Petrópolis (RJ): Vozes: 2001.

2. Santos VLCG, Ferraz AF, Diogo, AJD, Souza, RMC. A imagem de enfermeira e do enfermeiro percebida por alunos ingressantes no curso de graduação. Rev Bras Enferm 1988;41(3/4):241-51.

3. Silva AL, Padilha MICS, Borenstein MS. Imagem e identidade profissional na construção do conhecimento em enfermagem. Rev Lat-am Enfermagem 2002;10(4):586-95.

4. Ellis JR. Enfermagem contemporânea: desafios, questões e tendências. 5a. ed. Porto Alegre (RS): Artmed; 1998.

5. Uprichard M. Ferment in nursing. In: Auld E, Birum LH: The Challenge of Nursing. St Louis (MI): CV Mosby; 1973.

6. Angelo M, Forcella HT, Fukuda OMK. Do empirismo à ciência: a evolução do conhecimento em enfermagem. Rev Esc Enf USP1995 ago;29(2):211-23.

7. Germano RM. Educação e ideologia da enfermagem no Brasil. $2^{\mathrm{a}}$ ed. São Paulo (SP): Cortez; 1985.

8. Rodrigues MSP. De fada e feiticeira à sua imagem atual. A mulher enfermeira: cuidadora, gerente, pesquisadora. Texto Contexto: Enfermagem 1997 jan-abr;6(1):104-17.

9. Collière MF. Promover a vida. Da prática das mulheres de virtude aos cuidados de enfermagem. Lisboa (PT): Sindicato dos enfermeiros portugueses; 1989.

10. Padilha MICS, Nazario NO, Moreira MC. A compreensão do ideário da enfermagem para a transformação da prática profissional. Rev Bras Enferm 1997;50(3):307-22.
11. Padilha MICS. A mulher/enfermeira nos âmbitos doméstico-familiar e público: uma abordagem teórico-contextual. Rev Gaúcha Enfermagem 1994;15(1/2):5-12.

12. Takase $\mathrm{M}$, Kershaw $\mathrm{E}$, Burt L. Does public image of nurses matter? J ProfesI Nurs 2002 jul-ago;18(14):196-205.

13. Bashford A. Starch on the collar and sweat on the brow: self sacrifice and status of work of nurses. J Aust Stud 1997;(52):67-75.

14. Arthur D, Pang T, Wong MF, Alexander J, Drury H, Eastwood I, et al. Caring attributes, professional self-concept and technological influences in a sample of Registered Nurses in eleven countries. Int J Nurs Stud 1999:387-96.

15. Fullerton JT, Sukkary-stolba S. Advancing the status of nursing in Egypt: the project to promote the development of high institutes of nursing. Int J Nurs Stud 1995;32(5):518-24.

16. Rezende ALM. A Imagem da enfermagem numa perspectiva formista. Enfermagem Rev 1993;1(1):25-36.

17. Meyer DEE. Ao olhar-se no espelho, a enfermeira não tem gostado da imagem que aí vê refletida... Rev Bras Enferm 1992;45(2/3):17682.

18. Rizzoto MLF. História da enfermagem em sua relação com a saúde pública. Goiânia (GO): AB; 1999.

19. Lima MADS. Ensino de enfermagem: retrospectiva, situação atual $e$ perspectivas. Rev Bras Enferm 1994;47(3):270-7.

20. Sanna MC, Secaf V. A imagem da enfermeira e da profissão na imprensa escrita. Rev Enferm UERJ 1996 dez;4(2):170-82.

21. Carapinheiro G. Saberes e poderes no hospital. Porto (PT): Edições Afrontamento; 1993. 